\title{
Rear-Projecting Virtual Data onto Physical Terrain: An Exercise in Two Senses Being Better Than One
}

\author{
Dru Clark \\ Richard Marciano \\ Rosemarie McKeon \\ Michael Bailey ${ }^{1}$ \\ San Diego Supercomputer Center \\ University of California at San Diego
}

\begin{abstract} more readily apparent.

\section{Introduction}

Recent interest in the Tongass National Forest in Alaska has directed attention to the deforestation of the last remaining old growth rainforest in the United States, the largest temperate rainforest in the world. We were especially interested in Prince of Wales (POW) Island, Alaska. We wanted to produce an insightful visualization that would provide a meaningful interpretation of POW's deforestation as well as an indirect abstraction concerning fragmented wildlife habitat and potential paths of erosion.
\end{abstract}

This paper describes a project that combined physical model fabrication and virtual computerbased data display to create a unique visualization presentation. USGS terrain information on Prince of Wales Island, Alaska was used to create a physical prototype in SDSC's

TeleManufacturing Facility. This model was then used as a mold to create a translucent plate of the terrain. Finally, deforestation data from the island was color mapped and rear-projected onto the translucent plate within a light box. The result is a very compelling display in which both the senses of sight and touch are used to make relationships between terrain features and the data

POW is also an archeologically significant island. Norman MacLeod, a paleontologist at the British Museum of Natural History states:

"The fossils and artifacts those sites in Alaska provide, are points of light that allow us to understand how we came to our present position and predict what is likely to happen in the next ten, fifty, hundred or even thousand years."

We decided that traditional visualization methods such as color mapping scalar data (in this case the deforestation information) onto a computer-displayed 3D terrain map were not sufficient. We wanted to create more insight into the relationship between the terrain and the forest than could be generated by a

\footnotetext{
1 Authors' addresses: PO Box 85608

San Diego, CA 92186

dru@sdsc.edu rose@sdsc.edu marciano@sdsc.edu
}

computer display alone. We chose to experiment with combining both sight and touch in a single

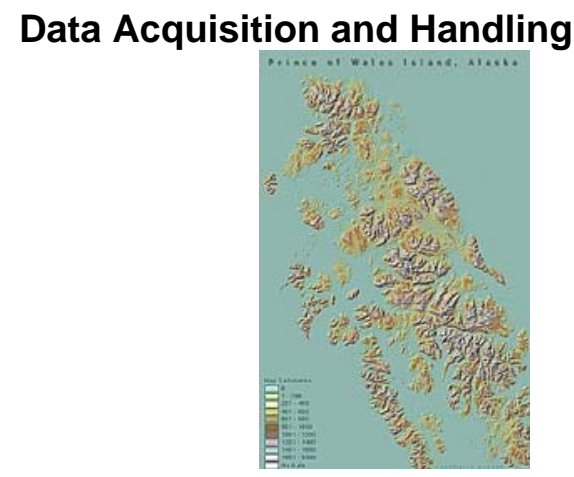

Figure 1: U.S. Forest Service Map

As shown in the map above, Prince of Wales Island is really a small collection of islands off the southeast coast of Alaska near the Canadian border. It stretches about 120 miles, and is part of the archipelago of islands that make up the Tongass National Forest. Its elevation varies from sea level to Mount Calder at 3340 feet, making some of its land very flat and other parts of it fairly steep and mountainous. Its population is about 7,000, mostly consisting of loggers, commercial fisherman, and descendants of Haida or Tlingit Native Americans. visualization. 
Figure 2 is a view from the space shuttle (courtesy of the Earthrise project) showing POW Island from 182 nautical miles.

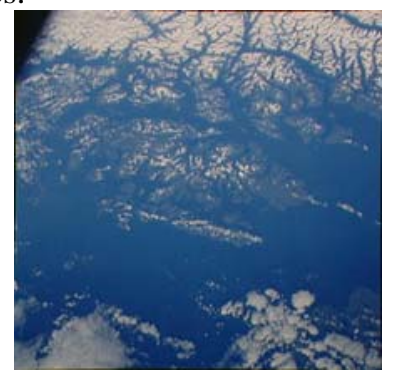

Figure 2: POW Island from Space

The terrain data we used to fabricate the model was obtained from the Alaska Geospatial Data Clearinghouse, a USGS-maintained site. This data forms the substrate of the geographic information system (GIS) database used by the Forest Service. GIS systems are computer-based tools for mapping and analyzing spatially referenced data. They integrate these capabilities with interactive map features. Such maps are typically used for planning strategies and predicting outcomes.

In order to compile a terrain data set for POW that could be used for the 3D model, we had to merge seven USGS quads (Figure 3): Port Alexander, Craig, Dixon Entrance, Petersburg, Bradfield, Ketchikan Canal, and Prince Rupert. The data resolution was 1:250,000 with a total of $3603 \times 3603$ elevation values for the combined 7 quads.

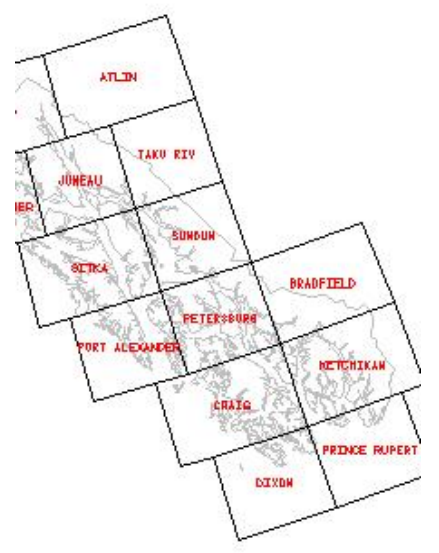

Figure 3: Individual Panels Combined into a Complete Dataset

Figure 4 shows the combined quad data. We used a Northwest convolution-filter-based viewer and then proceeded to crop out all sections of mainland and islands surrounding the island itself. Our final cropped-out version had 1401 x 2301 elevation values. The Forest Service uses this same trick to produce an elevation layer image (Figure 1) extracted from its GIS database which also contains dozens of other layers such as clearcut configuration and location, trees per acre, stream habitat characteristics, soil slide potential, and road location.

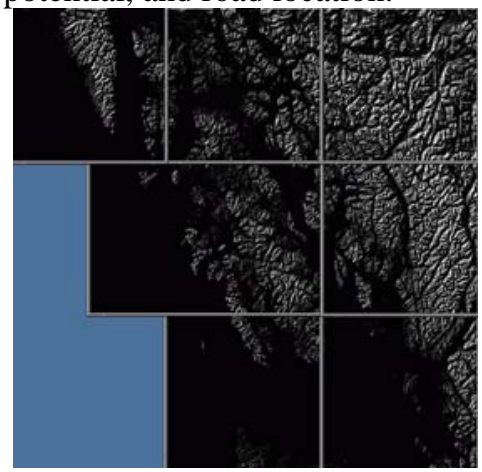

Figure 4: Individual Panels Combined into a Complete Dataset

The Forest Service deforestation data represents watersheds in which clearcuts occurred on United States forest land since $1954^{2}$. We color-coded green for intact forests and a yellow tinge where logging and clear cutting had occurred. This color-coded image was rendered and then copied onto two sheets of transparent plastic.

\section{Fabricating the Terrain Model}

The San Diego Supercomputer Center's (SDSC) TeleManufacturing Facility (TMF) [BAILEY95, CLARK97, TMF98] gave us a way to use a physical, rather than a virtual, 3D terrain model. The TMF houses a Laminated Object Manufacturing (LOM) machine, from Helisys, Inc. [LOM98]. The LOM machine is one of a number of commercially available Solid Freeform Fabrication (SFF) devices [BURNS93]. All SFF devices are categorized by being "additive manufacturing." The LOM machine fabricates its models by adding layers of laser-cut paper. Other SFF processes create models by adding layers or drops of plastic, resin, or powdered metal.

The LOM process is demonstrated below in Figure 5. The raw material is a roll of paper, .0042" thick, with heat-activated glue on the underside. For each layer, the paper is automatically rolled into place and laminated to the layers underneath it with heat and pressure. A laser then cuts out the outline of the part at that level. The process continues until all the

\footnotetext{
${ }^{2}$ Unfortunately, this dataset has omitted extensive private holdings on the western and southern sides of the United States.
} 
layers are completed. At each layer, the laser also crosshatches all areas that are not part of the actual object. When the fabrication is completed, these scrap areas are removed, revealing the final part.



Figure 5: The Laminated Object Manufacturing Process

Like most SFF machines, the LOM machine accepts the industry-standard STL file as input. The STL file format requires a list of 3D triangles that bound the outer skin of the volume to be fabricated. To produce the STL file for the POW model, the rectilinear elevation grid points were triangulated. Then, triangles were added on the sides and on the base to turn the terrain surface into a legal solid able to be manufactured.

The desired size of the model was larger than our LOM machine could handle, so the geometry of the STL file was split into four pieces. The resulting physical model, with all four plates connected, is shown below in Figure 6.

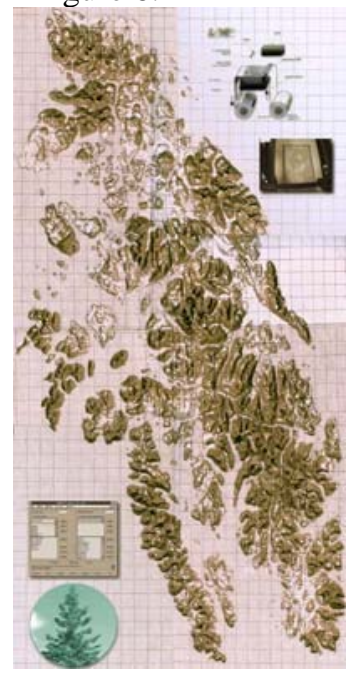

Figure 6: Final Physical Model from the LOM Machine

\section{Molding the Translucent Terrain and the Making the Light Box}

A mold was created from the four LOM-produced terrain plates. The four plates were firmly attached to each other and covered with a silicon mold-releasing agent. A box was built with about an inch of extra room on each side and the plates were placed inside facing up. The bottom of the box was sealed for leaks. We used Por-A-Mold Two-Part Urethane from Synair Corporation, which has a 24-hour cure time. Mold compound was poured to about one quarter inch above the highest elevation on the combined plates. This process created the negative image of the model, which would become the cast to produce the translucent positive. This cast is shown in Figure 7:

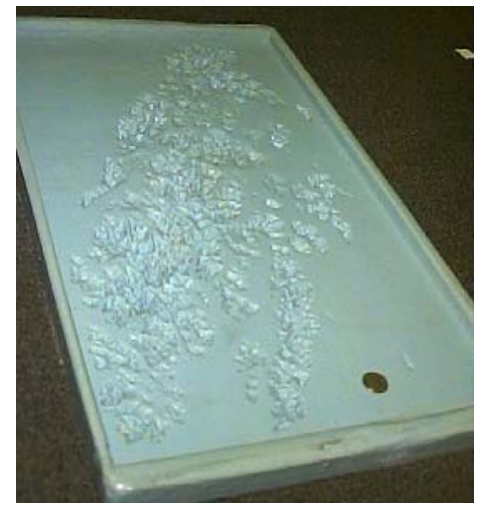

Figure 7: Negative Cast Created from Molding
Compound

When the mold was set, the plates were removed and both the cast and the original LOM plates were covered with more mold release. The casting of the final surface needed to be uniform in thickness to allow for uniform lighting when rear projected. A spacer of about one eighth of an inch was placed in the corners of the mold. A clear polyurethane casting resin was used and a minute amount of white pigment was added to make it translucent instead of transparent.

Caution was taken not to add too much catalyst. This would have created what is known as a hot batch, in which a large amount of heat is generated which can harm the mold and make the resin too brittle. With the cast facing up, the resin was poured into the cavity. The original LOM plates were then forced into the cast with the spacers maintaining a uniform gap for the resin being squeezed. Firm pressure was applied to the top against the spacers. The excess resin that oozed out the sides was wiped off in order to keep the edge clean. The casting was allowed to dry for about twenty-four hours. The clear casting was removed and cleaned of any imperfections.

A wooden light box was constructed and fitted with two fluorescent lights to project the color data. The transparencies of the color mapped data and the 
molded terrain became the lid of the box. This allowed the color data underneath to shine through the terrain mold.

\section{Results}

The results of this experiment are shown in Figures 8 and 9 . Figure 8 shows just the terrain mold. Figure 9 shows the lightbox turned on with the data shining through.

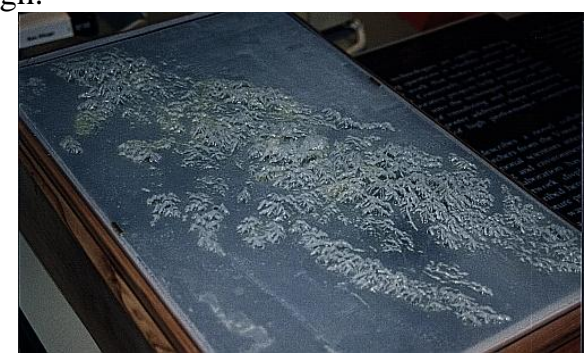

Figure 8: Lightbox with the Lights Off

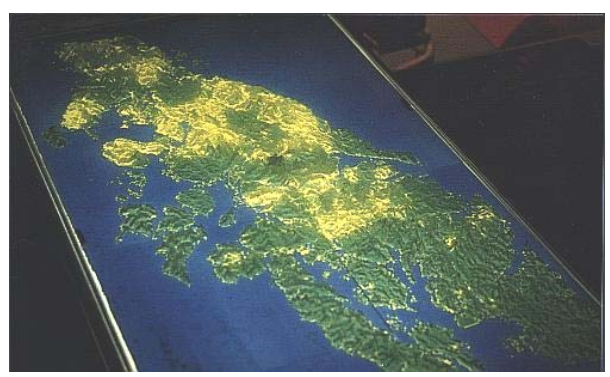

Figure 9: Lightbox with the Lights On

\section{Conclusions}

Better understanding of environmental issues is of great interest in interactive cartography. This method shows a unique way of combining virtual forestry database information with physical topological features. In addition, the sculpture inadvertently transmits a sense of place by locating bumpy twisting elevation changes specific to the island, as well as providing an intimate and powerful phenomenological and descriptive sense of "being there".

This particular experiment was static, that is, there was no interaction with the data other than running one's fingers across the surface of the terrain model. We see a great potential, though, in generalizing this approach to allow dynamic interaction. We are in the process of molding a United States terrain map to fit the bezel of a workstation monitor. This will allow us to extract GIS information on-the-fly, pulling it from large-scale distributed environmental databases, to produce on-demand images and animations that will be rear-projected from the CRT onto the physical terrain model. This will combine the potential of GIS technology and video-sculptures, a prospect that has interesting visual arts potential as well.

\section{Acknowledgements}

Much of this work was performed under NSF grant MIP-9420099. We thank the NSF for their support. We also thank Sun Microsystems for the workstation that front-ends the LOM machine.

We would like to acknowledge the collaboration of Alan Stein, researcher / historian / Prince of Wales environmentalist, and salmon fisherman. Alan is currently writing a book on the history, natural evolution, and deforestation of Prince of Wales Island. His enthusiasm, insights, and technical ideas shaped and guided many aspects of this study.

\section{Web Page}

For more information, see:

http: //www.sdsc.edu/tmf

\section{References}

[BAILEY95] Michael Bailey, "TeleManufacturing: Rapid Prototyping on the Internet with Automatic Consistency-Checking”, IEEE Computer Graphics and Applications, November 1995.

[BURNS93] Marshall Burns, Automated Fabrication, Prentice-Hall, 1993.

[CLARK97] Dru Clark and Michael Bailey, "Visualization of Height Field Data with Physical Models and Texture Photomapping”, IEEE Visualization '97, October 1997, pp89-94.

[LOM98] Laminated Object Manufacturing product literature, Helisys, Inc., 1998. Also see: http://www.helisys.com

[STL89] "Stereolithography Interface Specification”, 3D Systems, Inc., October 1989. 


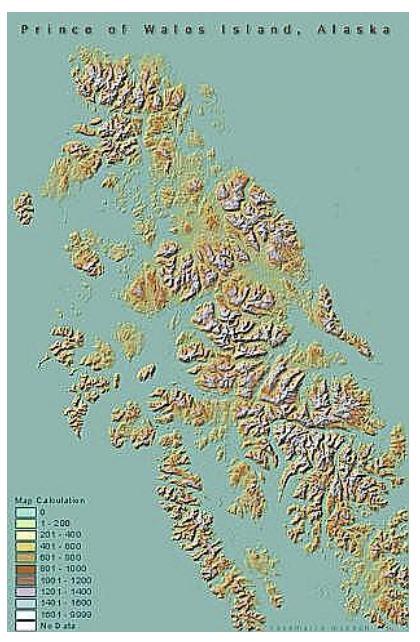

Figure 1: U.S. Forest Service Map

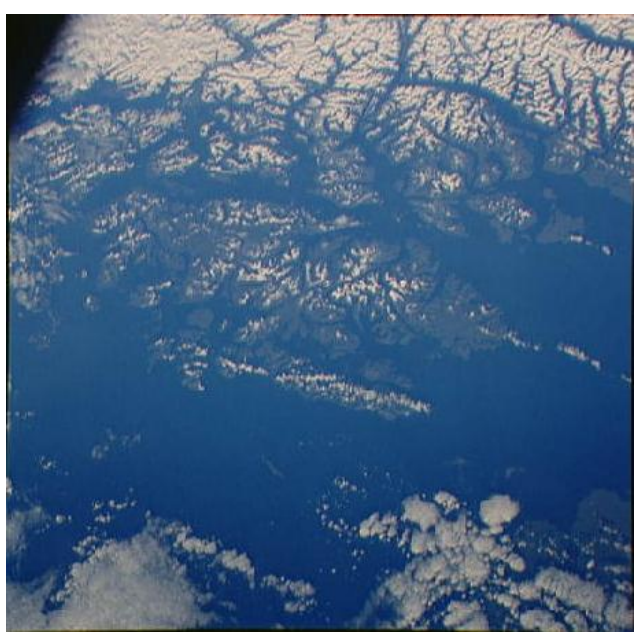

Figure 2: POW Island from Space

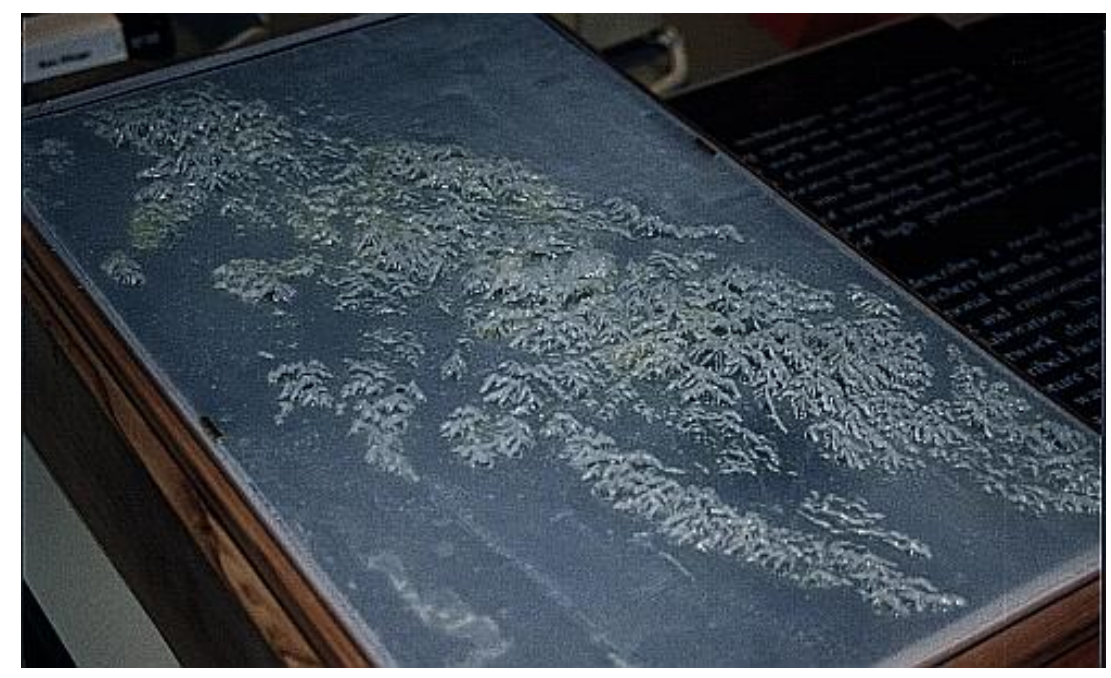

Figure 8: Lightbox with the Lights Off

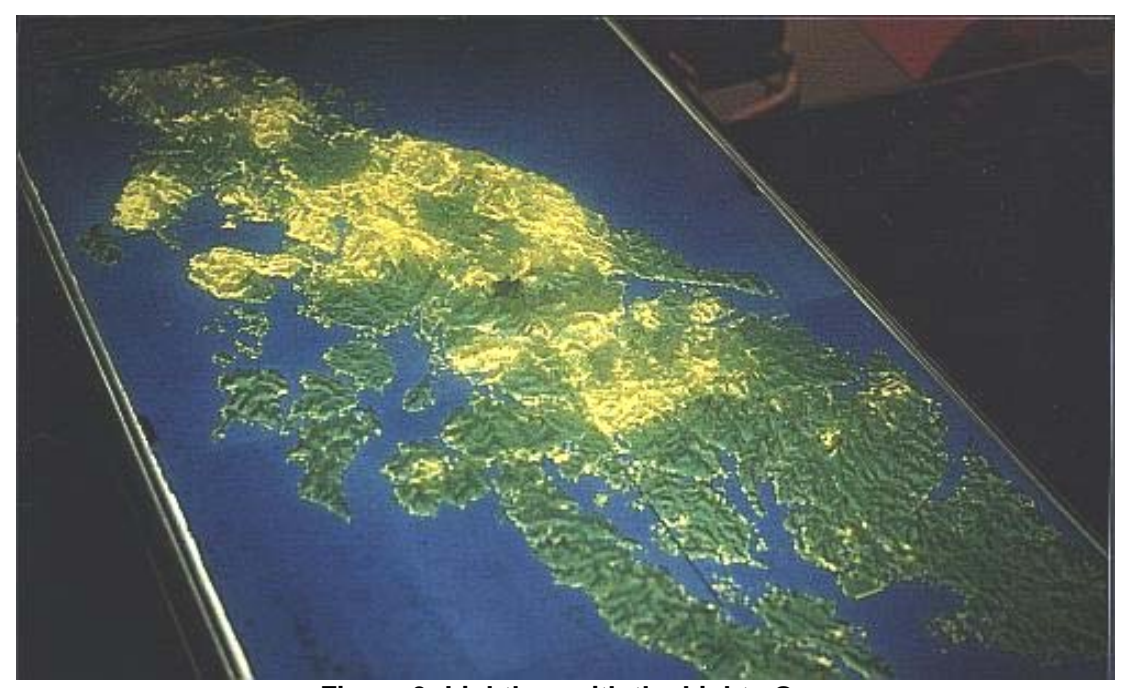

Figure 9: Lightbox with the Lights On 